\title{
ÇEHREDE SABİT ESER
}

\author{
Doç. Dr. I. Özer Kendi* - Yrd. Doc. Dr. Yaşar Bilge**
}

Müessir fiiller Adlî Tıbbın önemli bahislerinden biri olup çehrede sabit eser konusunun da bu bahis içerisinde özel bir yeri vardir.

TCK 456. maddesinde "(Değişik) Her kim katil kastı ile olmaksızın bir kimseye cismen eza verir veya sıhhatini ihlâle yahut akli melekelerinde teşevvüş husulüne sebep olursa altı aydan bir seneye kadar hapsolunur. (Asliye).

Fiil, havastan veya azadan birinin devamlı zaafint yahut söz söylemekte devamlı müşkülâtı veya şehrede sabit bir eseri yahut yirmi gün ve daha ziyade akli veya bedeni hastalıklardan birini veya bu kadar müddet mutat iştigallerine devam edememesine mucip olmuş veya hayatını tehlikeye maruz kılmış veya gebe bir kadın aleyhine işlenipte vaktinden evvel çocuk doğmasını intaç etmiş ise, ceza iki seneden beş seneye kadar hapistir. (Asliye)

Fiil, kat'i veya muhtemel surette iyileşmesi kabil olmayacak derecede akıl veya beden hastalıklarından birini yahut havastan veya el yahut ayaklardan birinin veya söylemek kudretinin yahut çocuk yapmak kabiliyetinin ziyaını mucip olmuş veya gebe bir kadına karşı ika olunup da çocuğun düşmesini intaç eylemiş ise, ceza beş seneden on seneye kadar hapistir. (Ağır Ceza)

Eğer fiil, hiçbir hastalığı veya mutad iştigallerden mahrumiyeti mucip olmamıs yahut bu haller on günden ziyade uzamamış ise takibat icrası mutazarnırın sikâyetine bağlı olmak şartı ile fail hakkında iki aydan altı aya kadar hapis veya ikiyüz liradan ikibinbeşyüz liraya kadar ağır para cezası hükmolunur. (Sulh)

* A.Ü. Tıp Fakültesi Adlî Tıp Anabilim Dałı Başkanı.

** A.Ü. Tıp Fakitltesi Adlî Tıp Anabilim Dalı Ổretim Üyesi. 
$\mathrm{Bu}$ fiil, 457. maddede yazılı vasıtalarla işlenirse, takibat icrası şikâyete bağlı değildir.

(Değiştiren Kanun No0 2275, 6123)

Not: Bu maddede yazılı para cezası 2790 Sayılı Kanunla "otuz misline çıkarılmıştır." denilmektedir.

Kanunda havastan veya azadan birinin devamlı zaafına söz söylemekte devamlı müşküilâta, yirmi gün veya daha ziyade akli veya bedeni hastalıklardan birini veya bu kadar müddet mutat iştigallerine devam edememeye, hayati tehlikeye maruz kalmaya veya gebe bir kadın aleyhine işlenip vaktinden evvel çocuk doğmasına sebep olunmuş fiiller ile basit bir yaralanma sonucu meydana gelen çehrede sabit eser için iki ilâ beş senelik hapis cezası öngöruilmüß̧̧ olması çehrede sabit eser konusunun önemini tebarüz ettirmektedir.

Pratikte de bu konu üzerinde dikkatle durulmalı ve Kanunun ruhuna uygun olarak raporlar tanzim edilmelidir.

\section{Çehre Nedir?}

Çehre "yüz" manâsında değildir. Başın üst kısmının (saçlı deri sınırından) başlayıp çenenin alt kısımlarına ve bir kulaktan diğer kulağa kadar olan çevre ve bu çevrenin görünüuşünï tamamlayan kısımlar "çehre" tabirini dahildir $(1,2)$

Manzini'ye göre çehre, alından çenenin ucuna ve bir kulaktan diğerine kadar olan kısmı kapsayan ve kişinin güzellik ve vekarını ençok ilgilendiren başın ön kısmıdır $(3,4)$.

Yazara göre, bir kulağın küçük bir kısmının kaybı, boyundaki bir yara izi çehrede sabit eser sayılır.

Adlî Tıp İşleri Meclisinin 9.8.1937 tarihli bir kararına göre Kanunda yazılı çehrenin fennen belli bir sınırı yoktur. Kanunun bu de-

1. Eren Faruk, Toruslu Nevzat, Türk Ceza Hukuk Özel hükümler, Sevinç Matbaası, Ankara, 1978. Sayfa: 473-474.

2. Eren Faruk, Türk Ceza Hukuku, Özel Hỉkümler, Ciit 3, Seçkiı Kitabevi, Ankara, 1985. Sayfa: $420-422$.

3. Çăglayan M. Muhtar, TCK, Ayyıldız Matbaası Ankara, 1962. Sayta: 334-356.

4. Dönmezer Sulhi, Kjşilere ve mala karşı cürümler, Faküilıeler Matbaası, 1stanbul, 1981. Sayfa: 116-123. 
yimi fenni bir temele değil tamamıle estetik yâni güzelliğe etki bakımından bir kişinin yüzünün genel gösterişine bağlı bir şey olduğundan bu husustaki taktir mahkemenin yetkisi çerçevesindedir.

Kanunumuzun kaynağı eski Italyan Kanununa ait gerekçede çehre sözcüğünün karşılığı olarak kullanılan "viso" kelimesi izah edilirken "başın ön tarafında alından çenenin alt ucuna ve kulaktan kulağa kadar (kulak dahil) kısımdır" denilmiştir. İtalyan Yargıtayının birçok karanna göre de kulak dahil sayılmıştır(4).

4. (Ceza Dairesi (5.10.1950 E.9941, K.10600) "Yüze bakıldığı zaman göze çarpan bütün uzuvlann yüz mefhumuna gireceğini açıklamiştır.

Boynun çehre mefhumu içerisinde mütalâa edilip edilmeyeceği konusunda doktrinde itilaf mevcuttur. Bazı muiellifler boynun çehre hududu içerisine girdiğini bildirmekle beraber bazıları girmediğini belirtmektedirler.

\section{Sabit Eser Nedir?}

Çehredeki her nedbe kalıcı bir izdir. Ancak kanuni manâda bunların hepsi çehrede sabit eser değildir. Çehrede sabit eser bırakılmış olmasından neyi anlamak gerekeceği konusunda Yargıtay içtihatları üç yöndedir.

1- Adlî Tıp Işleri Meclisi çeşitli kararlanndan çehrede sabit bir eserin kalmış bulunup bulunmadığının belirlenmesinin bir tup ve fen işi olmadığı, bunun estetik bakımdan tespiti gerektiği tezini öne sürmüştür. Meselâ, 1939 yllında verdiği bir kararında meclis, "raporda yazılı olup burun üzerinde görülen yara yeri sabittir, zaman ile silinip geçmez, ancak bunun çehrede sabit eser olup olmadığının taktiri bir fen işi değildir" demiştir.

Adî̂ Tıp Iş̧leri Meclisinin bu husustaki görüşü 18.7.1944 tarih ve 1676 sayilı raporu ile de tekrarlanmıştır.

Bir yaranın yüzde bıraktı̆̆ izin sabit olup olmadığının, yani zamanla silinip görünmez bir hale gelip gelmediğinin tesbiti tabiatıyla ilim, fen ve tıp işidir $(1,3,4)$. Böyle bir izin sabit olduğu anlaşldtktan sonra onun TCK. nun 456. maddesinde yazılı çehrede sabit eser sayılıp sayılmayacağı işine gelince, kanunun başka yerlerdeki yara izlerini söz konusu etmeyerek yalnız çehredekine 
önem vermesi ve bunun devamlı zaaf ve uzun tatili gibi sıhhat ve iş kabiliyetinden ayn olarak göze alınmasından anlaşılacağı üzere buradaki amaç tame:ıuyle şekil ayıbıdır. Bir yara izinin şekil ayıbı sayllacak türden olup olmadığının taktirinin ilim ve tıp bilgileriyle ilgisi olmaması gerekir. $\mathrm{Bu}$, bir ilim ve fen adamı olan bir hekimin bu konuda bir düşünce ileri süremeyeceği demek olmayıp bu husustaki ölçü ve kriteryumun ilim ve fen kaide ve usülleri değil o izin yaralının yüzünde çirkinlik yapan veya yaralının normal durumuna tesir edebilen bir eser sayılıp sayılmayacağı esasını göz önüne almaktır. Buna göre aynı yerde, aynı şekil ve mahiyette olan iz, yaralının cinsine, sosyal durumuna, bulunduğu ve yaşadığı muhitin görüş ve düşüncelerine göre çehrede sabit eser sayllabileceği halde başka birinde böyle olmayabilir. Bunda o izin bazı yollarla gözden saklı tutulabilmesi imkanının da yerine ve derecesine göre tesiri olabilir (4).

Iş̧e, bu düşünceler tesiriyledir ki, Adlî Tıp İşleri Meclisi kendisini bu işlerle kompetan görmediği gibi işleri ve kriteryumları ilim, fen ve sanat kaide ve usullerine dayanan anatomi enstitüsü ve Güzel Sanatlar Akademisini de bu sahada kompetan görmemektedir. Mahkemenin bu işlerde yaralının cinsine, sosyal durumuna, yaşadı̆̆ ${ }_{1}$ yer ve bulunduğu muhite göre o çevrede genel hak telâkkilerini bilip uygulayabilecek ve tabiatıyla her olayın özelliklerine göre başka başka kimselerden teşekkuilü gerek olacak bir ekspere ve yerine ve işine göre birkaç ekspere başvurması uygundur. Eksper seçimi işinde iki tarafın oy ve düşünceleri de alınabilir. Yargıtay da çeşitli kararlarında aynı içtihadı uygulamakta idi.

2- Ancak Ceza Genel Kurulu 8.10.1945 tarih E. 4-214 K. 225 sayılı kararı ile bu hususta tamamıyle başka bir görüşü uygulamış bulunmaktadır. "Kanunda sadece çehrede sabit eser denilmiş olup eserin ne gibi vasıfları haiz olması lâzım geleceği hakkında bir kaydı ihtiva etmediği gibi güzelliği ihlal edecek vasıfta bulunması lâzım geleceğine dair bir mana da istimzac edilmemekte olmasına ve eserin güzelliği bozar şekilde olması kabul edildiği taktirde hattızatında çehresi çirkin olanlarda husule getirilecek sabit eserin cezayı teşdit sebebi teşkil etmemesi lâzım geleceği gibi bir netice hasıl olacağına ve esasen tabii halde bulunan bir çehrede yaralama sebebiyle husule gelen sabit bir eserin az dahi olsa eskisine nisbetle bir çirkinlik vermesi tabii bulunmasına ve kaldı ki mağdurun çehresindeki sabit eser mahkeme huzurunda 16.12.1943 giinü duruşmada bilhassa görülerek tesbit edilmiş ve ona göre hüküm verilmiş oldu- 
gu beyanıyla eski hükmünđe ısran mutazammın Istanbul Asliye 6. Ceza Mahkemesinden bu kere verilen 10.1.1945 günlü hükmün dahi temyizen incelenmesi sanık tarafından süresi içinde verilen dilekçe ile istenilmesine ve şartı yerine getirilmiş olmasına binaen bu işe ait dava dosyası Cumhuriyet Başsavcllığınca bozma ilâmunda gösterilen sebep yerinde olup uyma gerekli iken eski hükmünde ısrar edilmesi yolsuz görüldüğünden hükmün bozulması isteğini bildiren tebliğname ile birlikte Birinci Başbakanlık Dairesine gönderilmekle Ceza Genel Kurulunda iş anlaşıldıktan sonra görüşüllüp düşünüldü.

Geçen yargılama sonuçlanna ve dosya arasındaki belgelere ve dayandığı gerekçelere göre ısrar kararı usul ve kanuna uygun bulunmuş olmakla yerinde görülmeyen temyiz itirazlarının ve tebliğnamede yazılı düşüncelerin reddine meskür hükmün onanmasına oy birliği ile karar verildi." Keza Ceza Genel Kurulu 16.12.1946, E.282, K.281, 13.1.1949, E.4-361-97, K.79 sayılı kararinda da bu görưş belirtilmiştir.

Görülüyor ki bu kararı ile Yargıtay artık yukarıda nakledilen Adlî Tıp kararını esas almaktan vazgeçmiş ve yüz güzelliğine olan etkiyi araştırmaksızın sadece sabit eserin varlığını 456. maddenin 2 . fıkrasındaki bu halin uygulanması için yeterli saymıştır.

3- Nihayet üçüncü yöndeki karan ile Yüksek Mahkeme bu konuda estetik ve surf hukuki kıstas yerine "sabit eserin yüzün tabii görünüşüne tesiri ölçüsünü koymuş bulunmaktadır. Yargıtay'ın yeni içtihatlarından sürülen bu görüşü̉n sistematizasyonunu şöylece yapabiliriz: Çehrede müessir fiil neticesi meydana çıkan eserin tıbbi anlamda sabit olup olmadığını tesbit tıbbi bir konu teşkil ettiğinden herşeyden önce bu hususun belirtilmesi gerekir. (4. Ceza Dairesi 12.5.1955, E.3231, K.9337 kararına göre "Izin sabit eser niteliğinde bulunup bulunmadığının ve zamanla zail olup olmayacağının Adlî Tıp Işsleri Meclisinin ilmi ve kat'i mütalâası alınmadan estetik kıstası müsteniden hükmün tesisi kanuna aykırı" görülmüştür.) Eserin böylece tıbbi bakımdan sabit olduğu anlaşıldıktan sonra, söz konusu eserin yüzün tabii görünïşüne olan etkisi araştır1lir.

Eserin yüzün tabii görüşünüuse etkisi olup olmadığını belirleme konusundaki kıstas ise şudur. Eser (nedbe) uzaktan bile görülebiliyor ve belirli bir dikkất sarfetmeksizin fark edilebiliyorsa yüzün 
tabii görünüşünü etkilemiş sayılması gerekir $(1,5,6)$. Buna karşılık ancak yakından ve dikkât edilmesi halinde farkedilebilecek bir eser sözkonusu ise yüzün tabii görünüşünü etkileyen bir durumun bulunduğu kabul edilmemelidir (4. Ceza Dairesi 21.3.1952, E.2924, K.2924). Etkiyi tesbit bakımından mağdurun sosyal durumu gözönünde tutulamaz (4. Ceza Dairesi 3.5.1952, E.4741, K.4736).

$\mathrm{Bu}$ nedenlerle yüzün tabii görünüşünü etkileme ölçüsü estetik ölçïye göre daha doğtu ve hukuk esaslarına uygundur. Zira, güzel veya çirkin olsun her insanın kendine ait olan ve hayatın zamanla şekillendirdiği yüz şeklini muhafazaya hakkı vardır ve bu şekilde çehresi onun kişiliğinin bir parçasıdır. Bir kimsenin yüzünün tabii görünüşünü etkilemiş bulunan sabit eseri 456 . maddenin 2 . fikrasına uygun saymalıdır. (7)

Adlî Tıp Meclisi 14.6.1957 tarih ve 10292, 5014 sayılı kararı ile bir kulak sayvanının dipten kesilmesi halinde çehrede sabit eser meydana gelmiş bulunacağına karar vermiştir. Ayrıca fasial sinir paralizisi, gözün fonksiyonel arazları da çehrede sabit eser açısından dikkatle değerlendirilmelidir.

Yara iyileşmesi ve zamanı da çehrede sabit eser konusunda önem arzetmektedir.

Yara İyileşmesi

Deri ve derialtı dokusunu ilgilendiren her yara iyileşirken bir nedbe (skatris) bırakır. Bir dokuda nedbe teşekkuil ettikten sonra yerinde sabit bir iz kalır. Çehrede sabit eser olarak değerlendirilmesi gereken bu iz olduğundan yaranın iyileşmesi ve iyileşme süreci de bilinmelidir.

Yara iyileşmesi (şifası) iki şekilde olur.

1- Pirimer yara şifası: Bu tür yara şifası genellikle aseptik metodlarla tedavi edilen yaralara hastır. Bu yaralarda dokular gayet çabuk ve ideal bir şekilde bir eser ve anatomik olarak bir nedbe

5. Kamay Behçet, Adlî Tıp, Gilzel Istanbu! Matbaası, Ankara, 1959, Sayfa: 621-622.

6. Özen Cahit, Sözen Hayri, Adlî Tıp ve Toksikoloji, Sermet Matbaası, Istanbul, 1971. Sayfa: 222-223.

7. Polat O., Inanıcı MA., Aksoy M.E., Adli Tıp, Nobel Tıp Kitapev!eri: Ltd. Şti. Sayfa 179-180, Istanbul, 1997. 
veya fizyolojik olarak fonksiyonel bir kusur brrakmadan iyileşir (8).

Yara husule geldikten sonra dokuda meydana gelen defektin içi kanla dolar ve kan pıhtılaşır. Bu pıhtılaşan kan kitlesi yarığı kapatarak yara yeri su kaybına ve infeksiyona karşı korur $(9,10,11$, $12,13,14,15)$.

Kan pthtılaştıktan sonra 24 saat içinde yara çevresinde lökositler, monositler ve lenfositler infiltre olur, sıvı eksuda ile şişer. Ölü doku hücrelerinden açığa çıan otolitik enzimler, nötrofillerden çıkan proteolitik enzimler ile monositlerin ve doku makrofajlarının fagositik aktivitesi birleşerek nekrotik dokuyu, hücre kırıntılarını ve eritrositleri ortadan kaldırurlar. Birkaç saat içinde yara kenarındaki epidermis kalınlaşır, iki taraftan aşağıya ve yara boşluğunun yukarı kısmı içine göç ederek yukarı dermis içinde birbiriyle birleşir. Mitolojik aktivite yalnız yara kenarına komşu bazal hücrelerde bulunur. 12 saatlik yara kırmizı ve ödemlidir. 24 saatten sonra vasküler tomurcuklanma başlar. Kapiller ağ 36 saatten sonra teşekkül eder. 36-48. saatte yeni damarlar deri yüzeyine doğru gelişme gösterirler. Yara kenarındaki epitel 24. saatten 48. saate doğru göçe başlar $(13,20,21,22)$.

Karşılıklı yüzleri çok iyi bir şekilde birbirine uyan yaralarda çoğu kez 48 saat içinde epidermis tabakası oluşur. Mc. Minn'e göre de epitel yara yüzeyine 24-48 saat içerisinde göç etmeye başlar ve hayvanlarda bu rejenerasyon hızı (epitelizasyon hızı) guinlük 0,2 $\mathrm{mm}$. dir. Lindsay ve Birch'in gösterdikleri gibi epitelyal hücreler

8. Dailey J.C., Bowers C.M., Aging of bitemarks: A literature review, J. Forensic Science 42/5: 792-795, 1997.

9. Anderson W.A.D., Pathology, The C.V., Mosby Company St. Louis, 1961, Sayfa: 54-67.

10. Ayral M. Naci ve arkadaşlan, Genel Cerrahi, Ankara Üniversitesi Basımevi, Ankara, 1972, Sayfa: 7-34.

11. Dunphy, J. Englebert, Way Lawrence Current Surgical Diagnosis Treatment, 1979, Beirut, Lebanon 1979, Sayfa: 990-991.

12. Kayabalı Ismail, Genel Şiriiri Ders Kitabı, A.Ü. Basımevi, Ankara, 1973- Sayfa: 44-48.

13. Peacoch, Erle E, Wound Repair WB Saunders Company, 1984, Sayfa: 35-36.

14. Polson, Cyril John and Gee, D.J. The Essentials of Forensic Medicine Pergemon Press Braunschweig, 1973. Sayfa: 148-149.

15. Robbins Stanley L. Texbook of Pathology, W.B. Saunders Company, PhileadelphiaLondon, 1966. Sayfa: 84-92. 
yara kenarlarından aşağıya derine doğru da gelişirler. 2-3. günlerde retikulum 5. günde yeni kollajen ortaya çıkar, tamir belirgin hale gelir ve fibroblastlar yüzeye paralel olarak belirginleşirler. 5-6. günlerden sonra yarada sertleşme başlar ve görünüşü kırmızımtrak veya mavimtrak skar (nedbe) dokusu şeklindedir. 2. haftada kollajenin azaldığı dikkatî çeker. 14. günün sonunda skar dokusu halâ yumuşak ve hassastır. Duyu sinirlerinin yara bölgesine doğru ilerlemesi ve epidermis altına gelmesi 3 . hafta sonunda görülür, ancak özel sinir sonlanmaları oluşmaz. 3. hafta sonunda vaskuiler olmayan nedbe dokusu teşekkül eder. 4. hafta içinde hücresel ve damarsal elemanlar sayıca azalır ve seyrekleşir. Yüzeyel yaralanmalarda skar dokusu gelişir. 2, aydan sonra az olmakla birlikte 6 . aya kadar renk değişikliği devamedebilir ve kahverengi veya bakır kırmızı rengini alır. 6. aydan sonra skar dokusu beyaz renktedir. Bundan sonra bir değişiklik göstermez. Bu skar dokusunun oluşumu bir homeostatik denge sonucudur(18).

Yüzeyel sıyrıklarda epitelizasyon 4-5 günde tamamlanır.

2- Sekonder yara şifası: buna cerahatlanma ile yara şifası adı da verilmektedir. Burada da temel, primer yara şifasında olduğu gibidir fakat hem iltihabi reaksiyon hem de yeni doku gelişmesi çok daha geniş olmakta, uzun zaman sürmekte ve çoğunlukla olduğu gibi düzenini yitirmekte, gerek anatomik olarak (nedbe), gerek fizyolojik yönlerden (fonksiyonel) aksakhklar ortaya çıkmaktadır. Burada yara şifası primer yara şifasında olduğu gibi bir rejenerasyon değil bir reparasyon (onarım)dur. Yara dudakları arasını bol miktarda bağ dokusu doldurur. Bağ dokusunun olgunlaşması aylar sürer. bu süre içinde bağ dokusu başlangıçtakine oranla daha az hücreseldir v e kapiller damarların azaldığı dikkati çeker. Bu devrede yaradan yapilacak histolojik inceleme, kollajenden zengin hücreden fakir bir bağ dokusu gösterir. Daha sonraları kollajen şekilsiz bir kitle haline gelir. Yani hyalinizasyona uğrar. Önceleri pembe renkte olan nedbe dokusu sonraki aylarda damarlaşmanın azalması sebebiyle beyaz renk alır $(19,20,21,22)$.

16. Glaister John and Rentonl Edgar, Medical Jurisprudence and Toxicology E. and S. Livingstone Ltd. Edunburg and London, 1996, Sayfa: 79-60: 265.

17. Raekallio, Jyrk1, Timing of Wounds, Adlî Tıp Dergisi 1, 1985, Sayfa: 3-21.

18. Gök Şemsi. Adlî Tıp, Filiz Kitabevi, Istanbul, 1983. Sayta: 265-267.

19. Boyd William, A Texbook of pathology, Lea and Febiger Phileadelphia, 1963, Sayfa: 68-74. 
Çehrede sabit eser muayenesi ne zaman ve nasıl yapılmalıdır?

Bazı yaralar bariz bir nedbe bırakmadan iyileşebilirler. Bu tür vak'alar önem arzetmezler. Ancak bazı nedbeler de 4-5 ay sonra kaybolabilirler ve bunlarda çehrede sabit eser sayılmazlar. Kuşkulu durumlarda kesin karara varabilmek için yukarıda da belirtildiği veçhile nedbeleşmenin tarz teşekküliü ve renk değişikliğin tamamlanmasının temini bakımından muayenin yaralanmadan 6 ay sonra yapılmasi uygun olacaktir $(18,23)$.

Şahsın çehresindeki nedbe yaklaşı 4-5 m. lik bir mesafeden (herhangi bir dikkât sarfetmeden) kolaylıkla görülebiliyorsa bu tür nedbeler yüzün tabii görïnüşünü etkilemiş sayılırlar ve kanuni manâda çehrede sabit eser kapsamına girerler $(24,25)$.

\section{MATERYAL VE METOT}

Çehrede sabit eser ile ilgili olarak 1968-1988 yılları arasında Anabilim Dalımıza gönderilen 584 vakanın rapor kopyaları incelenmiştir. Bunlar arasında 10 vakada nedbeleşme tamamlanmadığından kesin kanıya varılamadığı ve tekrar muayeneye çağrıldıkları tesbit edilmiş olup 574 vaka değerlendirmeye tabi tutulmuştur.

\section{BULGULAR VE TARTIŞMA}

Tablo I Cinsiyet ile çehrede sabit eser arasındaki ilişki

\begin{tabular}{|l|c|c|c|c|c|c|}
\hline Cinsiyet & Sayı & Yüzde & $\begin{array}{c}\text { Sabit Eser } \\
\text { Niteliğinde } \\
\text { Bulunan }\end{array}$ & Yüzde & $\begin{array}{c}\text { Sabit Eser } \\
\text { Niteliğinde } \\
\text { Bulunmayan }\end{array}$ & Yïzde \\
\hline Kadın & 153 & 26.66 & 48 & 6.36 & 105 & 18.29 \\
\hline Erkek & 421 & 73.34 & 137 & 23.87 & 284 & 49.48 \\
\hline Toplam & 574 & 100 & 185 & 32.23 & 389 & 67.77 \\
\hline
\end{tabular}

20. Bulay Orhan, Hücre zedelenmesi lokal dolaşm bozukluklan, iltihap, immünite ve timus hastalıkları, Ankara Universitesi Basımevi, 1984, Sayfa: 132-140.

21. Değerli Unal, Genel Cerrahi, Fathh Gençlik Vakfı Matbaa Işletmesi, İstanbul, 1983, Sayfa: 27-42.

22. Robertson I and Hodge P.R. Histopathology of Healing Abrasion Forensic Science 1, 1972, Sayfa: 17-25.

23. Aykaç Mehmet, Adłî Tıp Ders Kitabı, Çeliker Matbaacılık, İstanbul, 1987, Sayfa: 227

24. Öztiirel Adnan, Adlî Tıp, Olgaç Matbaası, Ankara, 1983, Sayfa: 1999-200.

25. Tunalı tbrahim, Adli Tıp, Yarıaçık Cezaevi Matbaası, Ankara, 1988. Sayfa: 99. 
Tablo I de görüldüğü gibi bu vakaların 153 'ü (\%26.66) kadın, 421 i (\% 73.34) erkek olup kadınların 48'inde (\% 8.36) erkeklerin 137 'sinde (\% 23.87) yaraların çehrede sabit eser niteliğinde bulunduğu tesbit edilmiştir.

Kadinların 48'inde (\% 8.36), erkeklerin 137'sinde (\% 23.87) çehresinde sabit eser niteliğinde nedbe tesbit edilmiştir. Literatürde kadınlarda keloid teşekkuilünün daha fazla olduğu kaydedilmekte ise de bizim vakalarımızda istatistiki olarak her iki cins arasında anlamlı bir farklılık bulunmamıştır.

Tablo II Yaş ile çehrede sabit eser arasındaki ilişki.

(574 vakanın 470'inde yaş belirtilmiş olduğu için tablo buna göre düzenlenmiştir).

\begin{tabular}{|c|c|c|c|c|}
\hline $\begin{array}{l}\text { Yaş } \\
\text { Yll }\end{array}$ & $\begin{array}{l}\text { Sabit Esser } \\
\text { Niteliginde } \\
\text { Bulunan } \\
\end{array}$ & $\begin{array}{l}\text { Sabit Eser } \\
\text { Niteliğinde } \\
\text { Bulunmayan }\end{array}$ & Toplam & Yüzde \\
\hline 0.5 & 4 & 5 & 9 & 1.92 \\
\hline $6-10$ & 7 & 4 & 11 & 2.34 \\
\hline $11-15$ & 11 & 19 & 30 & 6.38 \\
\hline $16-20$ & 24 & 37 & 61 & 12.98 \\
\hline $21-25$ & 27 & 60 & 87 & $18-51$ \\
\hline $26-30$ & 28 & 37 & 65 & $13-83$ \\
\hline $31-35$ & 31 & 35 & 66 & 14.04 \\
\hline 36.40 & 12 & 21 & 33 & 7.02 \\
\hline $41-45$ & 11 & 32 & 43 & 9.15 \\
\hline $46-50$ & 2 & 21 & 23 & 4.89 \\
\hline $55-55$ & 6 & 17 & 23 & 4.89 \\
\hline $56-60$ & 1 & 4 & 5 & 1.06 \\
\hline $61-65$ & 1 & 5 & 6 & 1.27 \\
\hline $66-70$ & - & 5 & 5 & 1.06 \\
\hline $72-5$ & - & 3 & 3 & 0.53 \\
\hline Toplam & $\begin{array}{c}165 \\
(\% 35.10)\end{array}$ & $\begin{array}{c}305 \\
(\% 54.90)\end{array}$ & 470 & 200 \\
\hline
\end{tabular}


Tablo 11 de görüldüğ̈i gibi, 16-35 yaş grupları arasındaki vakalarda sabit eser oranı diğer yaş gruplarındakilerden daha yüksek bulunmuştur.

Tablo III Çehredeki yara nedbelerininin yerleri ile sabit eser arasındaki ilişki.

\begin{tabular}{|l|c|c|c|c|c|c|}
\hline Yara Yeri & Sayı & Yüzde & $\begin{array}{l}\text { Sabit eser } \\
\text { Niteliğinde } \\
\text { Bulunan }\end{array}$ & $\begin{array}{l}\text { Yüzde } \\
(574 ' e \\
\text { göre })\end{array}$ & $\begin{array}{l}\text { Sabit eser } \\
\text { Niteliğinde } \\
\text { Bulunmayan }\end{array}$ & $\begin{array}{l}\text { Yüzde } \\
(574 ' \mathrm{e} \\
\text { göre })\end{array}$ \\
\hline Alın & 127 & 22.13 & 43 & 7.49 & 84 & 14.63 \\
\hline Göz Çevresi & 121 & 21.08 & 18 & 3.14 & 103 & 17.94 \\
\hline Yanaklar & 153 & 26.66 & 69 & 12.02 & 84 & 14.83 \\
\hline Burun & 60 & 10.45 & 19 & 3.31 & 41 & 7.14 \\
\hline Alt Çene & 30 & 5.23 & 14 & 2.44 & 16 & 2.79 \\
\hline Dudaklar & 35 & 6.10 & 6 & 1.05 & 29 & 5.05 \\
\hline Kulaklar & 41 & 7.14 & 16 & 2.79 & 25 & 4.36 \\
\hline $\begin{array}{l}\text { Yara Izi } \\
\text { Görülmeyen }\end{array}$ & 7 & 1.22 & - & - & 7 & 1.22 \\
\hline Toplam & 574 & 100 & 185 & 32.23 & 389 & 67.77 \\
\hline
\end{tabular}

Tablo III'ün tetkikinden anlaşılacağı üzere, çehresinde sabit eser niteliğinde iz bulunup bulunmadığının tesbiti istenilen vakalarda ilk sırayı $153(\% 26.66)$ ile yanaklarındaki, ikinci sırayı 127 (\%22.13) ile alınlarındaki, üçüncủ sırayı 121 (\% 21.08) ile göz çevresindeki yaralanmalar sebebiyle gönderilen vakalar almıştır.

Çehresindeki yara izinin sabit eser niteliğinde olduğu tesbit edilen vakalarda da yine ilk sıray $\% 12.02$ ile yanaklar, ikinci sırayı \%7.49 ile alın almış olup üçüncỉ sırayı \% 3.31 ile burun üzerindeki nedbeler teşkil etmiştir.

Gönderilen vakalardan 7'sinde (\% 1.22) çehrede herhangi bir nedbe tesbit edilmemiştir. $185^{\prime}$ 'ine (\% 32.23) çehrede basit eser bulunduğu, 389'una da (\% 67.77) çehrede sabit eser bulunmadığı şeklinde rapor tanzim edilmiştir. 


\section{SONUÇ}

Anabilim Dalımıza gönderilen 574 vakanın da değerlendirilmesinden anlaşılacağ gibi, çehredeki her nedbe sabit eser olarak nitelendirilmemelidir. Çehrede sabit eser konusunda rapor tanzimi istenildiğinde, gerekli muayene nedbeleşme tamamlandıktan sonra yapılmalı ve mevcut nedbenin yüzün tabii görünüşünü etkileme derecesi kıstas alınmalıdır.

\section{Anahtar Kelimeler: Cehrede Sabit Eser, Türk Ceza Kanunu \\ ÖZET}

Bu makalede çehrede sabit eser konusunun Adlî Tip açısından değerlendirilmesi yapılmıştır. Çalışmamızda bölümümüzdeki 574 vaka raporu retrospektif olarak incelendi. Bunlardan 185 i Türk Ceza Kanunun 456 ncı maddesinin 2 nci fikrasına göre çehrede sabit eser niteliğindedir.

Keywords: Fixed Scar of Face, Turkish Panel Code

\section{SUMMARY}

In this article fixed scar of face is discussed interference with forensic medicine. This study is investigated retrospectivly 574 report case in our department. 185 from them are fixed scar of face which is situated in 456/2 of Turkish Penal Code.

\section{KAYNAKLAR}

1- Eren Faruk, Toruslu Nevzat, Türk Ceza Hukuk Özel hükümler, Sevinç Matbaası, Ankara, 1978. Sayfa: 473-474.

2- Eren Furuk, Türk Ceza Hukuku, Özel Hükümler, Cilt 3, Seçkin Kitabevi, Ankara, 1985. Sayfa: 420-422.

3- Cağlayan M. Muhtar, TCK, Ayyıldız Matbaası Ankara, 1962. Sayfa: 334-356.

4. Dönmezer Sulhi, Kişilere ve mala karşı cürümler, Fakulteler Matbaası, Istanbul, 1981. Sayfa: 116-123.

5- Kamay Behçet, Adlî Tıp, Güzel İstanbul Matbaası, Ankara, 1959, Sayfa: 621-622.

6- Özen Cahit, Sözen Hayri, Aơlî Tıp ve Toksikoloji, Sermet Mabaası, Ĺstanbul, 1971. Sayfa: $222-223$.

7- Polat O., Inanı ı MA., Aksoy M.E., Adli Tıp, Nobel Tıp Kitapevleri: L.td. Şti. Sayfa 179-180, Ístanbul.

8- Dailey J.C., Bowers C.M., Aging of bitemarks: A literature review, J. Forensic Science 42/5: 792-795, 1997. 
9- Anderson W.A.D., Pathology, The C.V., Mosby Company St. Louis, 1961, Sayfa: 54-67.

10- Ayral M. Naci ve arkadaşlan, Genel Cerrahi, Ankara Universitesi Basımevi, Ankara, 1972, Sayfa: 7-34.

11- Dunphy, J. Englebert, Way Lawrence Current Surgical Diagnosis Treatment, 1979. Beirut, Lebanon 1979, Sayfa: 990-991.

12- Kayabalı Ismail, Genel Şirúrii Ders Kitabı, A.Ü. Basımevi, Ankara, 1973- Sayfa: 44-48.

13- Peacoch, Erle E, Wound Repair WB Saunders Company, 1984, Sayfa: 35-36.

14- Polson, Cyril John and Gee, D.J. The Essentials of Forensic Medicine Pergemon Press Braunschweig, 1973. Sayfa: 148-149.

15. Robbins Stanley L. Texbook of Pathology, W.B. Saunders Company, PhileadelphiaLondon, 1966. Sayfa: 84-92.

16- Glaister John and Rentonl Edgar, Medical Jurisprudence and Toxicology E. and S. Livingstone Ltd. Edunburg and London, 1996, Sayfa: 79-60: 265.

17- Raekallio, Jyrk, Timing of Wounds, Adlî Tıp Dergisi 1, 1985, Sayfa: 3-21.

18- Gök Şemsi. Adlî Tıp, Filiz Kitabevi, Istanbul, 1983. Sayfa: 265-267.

19- Boyd William, A Texbook of pathology, Lea and Febiger Phileadelphia, 1963, Sayfa: 68-74.

20- Bulay Orhan, Hùcre zedelenmesi lokal dolaşım bozuklukları, iltihap, immünite ve timus hastalıkJan, Ankara Üniversitesi Basımevi, 1984, Sayfa: 132-140.

21- Değerli Unal, Genel Cerrahi, Fatih Gençlik Vakf1 Matbaa İșlettmesi, Istanbul, 1983, Sayfa: 27-42.

22- Robertson I and Hodge P.R. Histopathology of Healing Abrasion Forensic Science I, 1972, Sayfa: 17-25.

23- Aykaç Mehmet, Adıî Tıp Ders Kitabı, Çeliker Matbaacılık, Istanbul, 1987, Sayfa: 227

24- Öztürel Adnan, Adlî Tıp, Olgaç Matbaası, Ankara, 1983, Sayfa: 199-200.

25- Tunalı Ibrahim, Adli Tıp, Yarıaçık Cezaevi Matbaası, Ankara, 1988. Sayfa: 99. 